\title{
Fluid Transient Analysis during Priming of Evacuated Line
}

\author{
By \\ Alak Bandyopadhyay \\ Computer Science, Alabama A \& M University, Normal, AL 35762 \\ $\&$ \\ Alok K. Majumdar, Kimberley Holt \\ Propulsion System Department, NASA Marshall Space Center, Huntsville, AL 35812
}

\begin{abstract}
Water hammer analysis in pipe lines, in particularly during priming into evacuated lines is important for the design of spacecraft and other in-space application. In the current study, a finite volume network flow analysis code is used for modeling three different geometrical configurations: the first two being straight pipe, one with atmospheric air and other with evacuated line, and the third case is a representation of a complex flow network system. The numerical results show very good agreement qualitatively and quantitatively with measured data available in the literature. The peak pressure and impact time in case of straight pipe priming in evacuated line shows excellent agreement.
\end{abstract}

\section{Nomenclature}

$\begin{array}{ll}A & =\text { Area } \\ \mathrm{K}_{\mathrm{f}} & =\text { Friction Factor } \\ L_{g} & =\text { Gas (air) column length } \\ L_{l} & =\text { Liquid (water) column length } \\ \mathrm{L}_{\mathrm{t}} & =\text { Total length of the pipe } \\ \dot{m} & =\text { Mass Flow Rate } \\ p & =\text { Fluid Pressure, psia } \\ \mathrm{p}_{\mathrm{air}} & =\text { Air pressure downstream of valve } \\ \mathrm{p}_{\mathrm{atm}} & =\text { Atmospheric pressure, psia } \\ \mathrm{p}_{\mathrm{R}} & =\text { Reservoir or supply pressure, psia } \\ \Delta p & =\text { Pressure Drop, psf (pounds per square feet) } \\ \mathrm{T} & =\text { Temperature, } \mathrm{F}\end{array}$

\section{Introduction}

Water hammer and Pressure surges are critical in the design of spacecraft propellant feed lines. The water hammer pressure transients that occur during priming of feed lines are very important in the design and analysis of liquid propulsion systems. During the start-up of the propulsion system of a spacecraft, the process of filling of an evacuated pipeline, is called priming. Priming can generate severe pressure peaks due to the slam (water hammer) of the propellant against a closed thruster valve. The downstream conditions strongly affect the pressure surge. In space systems, satellites, or interplanetary probes, the propellant lines are vacuum-pumped or filled with low pressure helium or nitrogen before the launch. Before operations, these lines are primed with a vaporizing liquid, sometimes in the presence of a non-condensable gas (NCG), which produces water hammer phenomena. These phenomena occur regularly in aerospace applications. There are many other applications as well, such as fuel injectors in engines, fire sprinklers, and water hoses etc. When a valve is opened, quick filling of lines produces a shock wave, known as water hammer which travels through the feed lines, induces pressure peaks and frequencies which can cause serious damage not only to the lines but with the associated equipment too.

The water hammer in pipe line have been studied by many authors in the past, experimentally, analytically and numerically. There have been a review of water hammer theory and practice done by Ghidaoui et al in 2005 [1]. However, there have been numerous works in this area since then, in particularly for aerospace applications [2, 3, 4, 5]. However, except for a few, not much study have been done in the area of priming, in particularly for priming in a flow network containing numerous flow components. Prickett et al [6] have done some testing of priming problem in straight pipe as well as in a flow network using water as a reference fluid. They have also compared their test data with simplified analytical model. Lecourt and Steelant [7] have used ethanol, acetaldehyde and a real propellant 
mono-methyl-hydrazine as a test fluid for priming in simplified feed lines. Bandyopadhyay and Majumdar [8] have studied the water hammer analysis in a closed pipe with entrapped air.

The objective of the current study is to use a finite volume based network flow solver by solving relevant governing equations to simulate the problem of priming to completely evacuated line as well as presence of low pressure air downstream of the valve. The numerical results are tested with data available from the measurement data of Prickett et al [6].

\section{Problem Description and Computational Model}

The water hammer problem in a pipe filled with water and entrapped air and in pipe (pipes) in evacuated lines are considered for this study. All the cases can be solved using similar algorithm. The three specific cases considered for the current study are: a) Water hammer pressure prediction in a straight pipe with entrapped air, b) priming in a straight evacuated pipe and c) priming in a flow network.

In the first case, water hammer in a closed pipe with entrapped air is considered; the physical geometry is shown in figure 1. In a long pipe with water reservoir to the left, the water region is initially on the left side of the ball valve (location CD) whereas the entrapped air is on the right side of the valve till the end of the pipe as shown in the figure. The pipe is $20 \mathrm{ft}$. long from the reservoir to the start of ball valve (designated by $\mathrm{L}_{1}$ in figure 1), and the gas or air column length $\left(\mathrm{L}_{\mathrm{g}}\right)$ varies depending on the ratio of air column length to total length. The ball valve starts opening gradually from $0.2 \mathrm{~s}$ to $0.5 \mathrm{sec}$ and it is fully open at $0.5 \mathrm{sec}$. The geometrical setup and operating conditions are identical to experimental setup of Lee [9]. This problem have been solved by Bandyopadhyay and Majumdar [8] using network flow solver. However, in that numerical model, the entrapped air region was lumped into a single node and the water to air interaction was accounted thermodynamically. The model was able to predict the peak pressure at the dead end with reasonable accuracy, however, that model was not able to predict the pressure distribution along the entire pipe length consisting both the water and air region. This drawback is overcome in the current model by using two fluids (water and air) and also by placing the ball valve in the correct geometrical location (section CD). The ball valve opening angle ( 0 : closed, 90 degree: full open) is shown in figure 2 as a function of time. In the numerical model, all the related equations (continuity, momentum, energy and species-concentration) are solved in the entire pipe length, not only in the water region unlike [8].

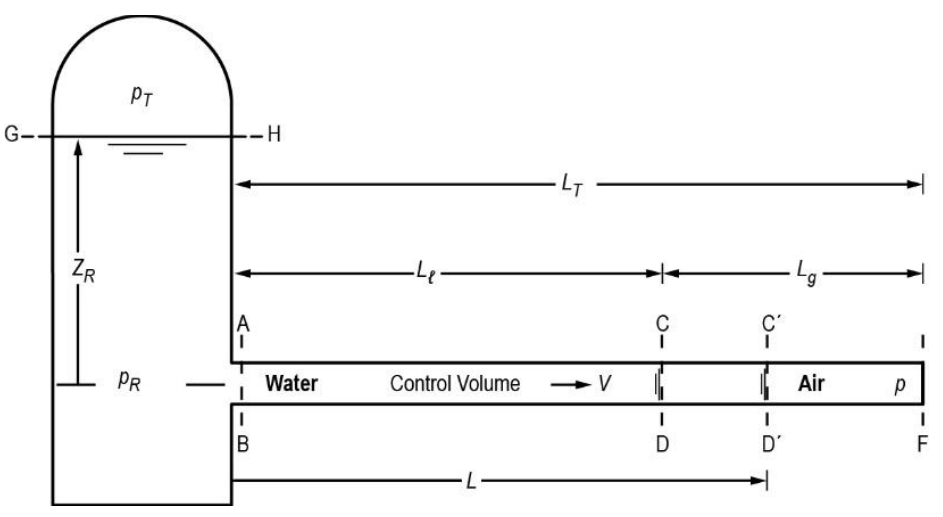

Figure 1. Schematic of the water pipe with entrapped air [Lee, 9]. 


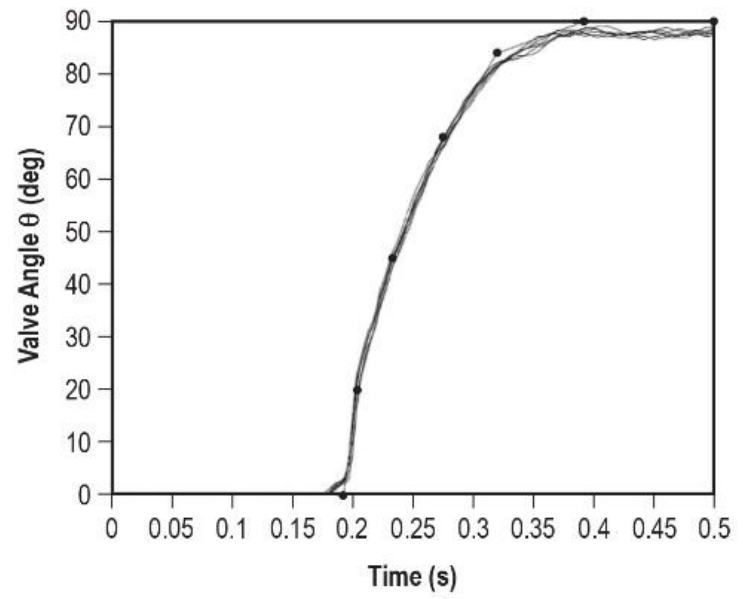

Figure 2. Ball valve angle change with time [9].

The computational model in which the entire pipe is divided into a set of nodes and branches as shown in figure 3 below. Node 1 represents the reservoir, which is a boundary node, and the restriction in branch 1112 indicates the ball valve. The ball-valve opening is provided to the solver through an input file where the time and valve area open at an instant are supplied. Node 20 represents the dead end. Each branch as shown in red color, represent a pipe segment of length 24 inches and pipe diameter of 1.025 inches. Increasing number of branches more than what are being used does not change the result. The details of the governing equations and solution procedure will be briefly described at the end of this section.

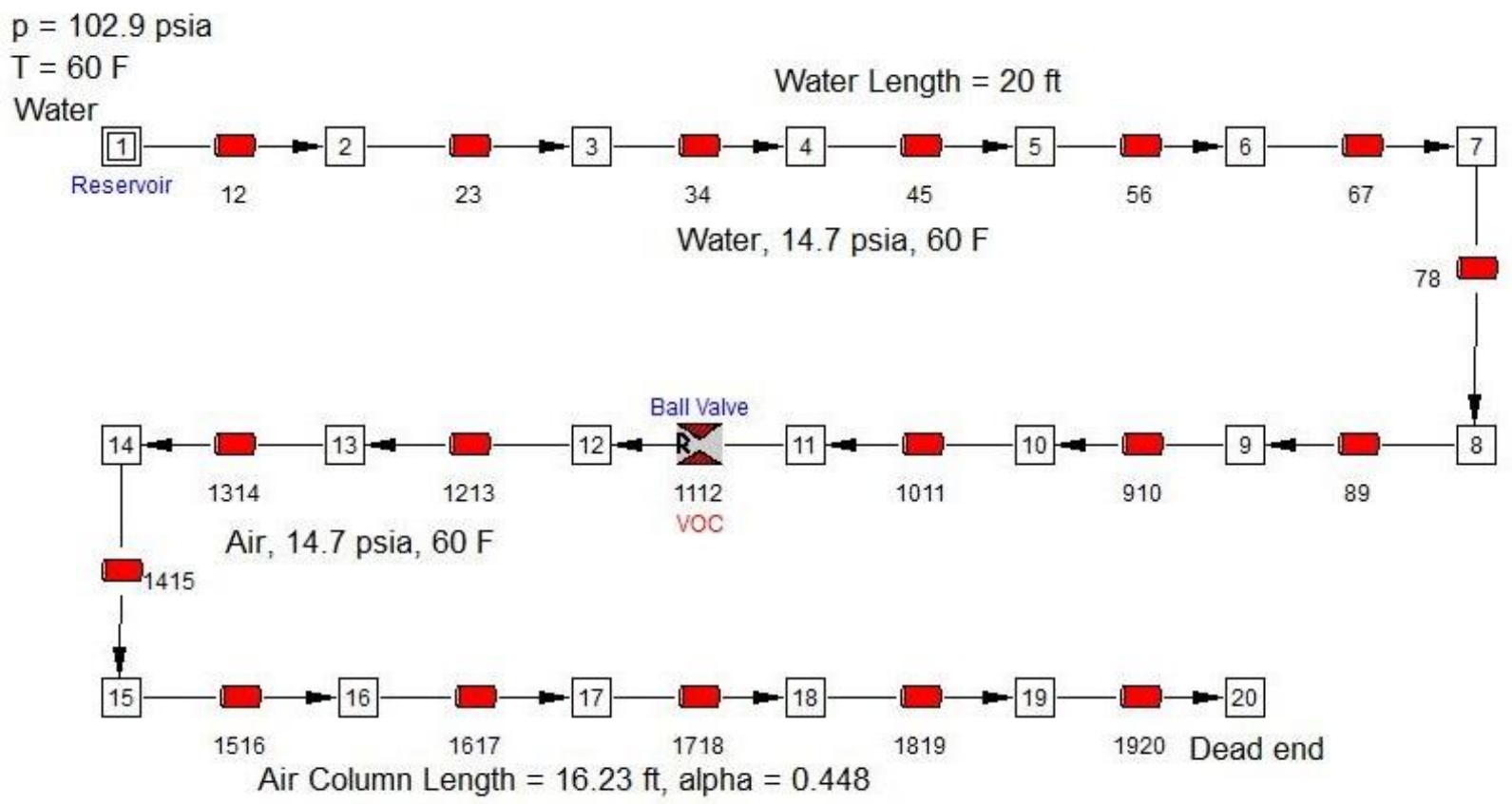

Figure 3. GFSSP Model for the Entrapped Air Pipe

The boundary node, node 1 is kept at reservoir (or supply pressure) $\mathrm{p}_{\mathrm{R}}$ which varies from $29.4 \mathrm{psia}$ to $102.9 \mathrm{psia}$ ( 2 times to 7 times more than standard atmospheric pressure). The water concentration at nodes upstream of valve 1112 , is fixed to 1 and air concentration to 0 . Similarly the air concentration in the downstream of valve, that is in nods 12 through 20 are kept at 0 (for water concentration) and 1 (for air concentration) respectively.

The next two cases are dealing with priming in feed lines, First priming into a straight pipe is considered as shown in figure 4 below. The geometry considered in the current research are identical to experimental study of Pricket et al [7]. In the figure shown are the reservoir on the left, pipe lines, hand valves (HV), the main supply valve (Latch Valve 
- LV), along with pressure transducers at three different points (P1, P2 and P3). The latch valve opens almost instantaneously, and water flows from the reservoir to the evacuated pipe. The pipe upstream of the latch valve is 12 inches long and 3/8 inches in diameter and the downstream of the latch valve, the pipe is 96 inches long and $1 / 4$ inches in diameter. The supply pressure varies from 30 psia to 120 psia.

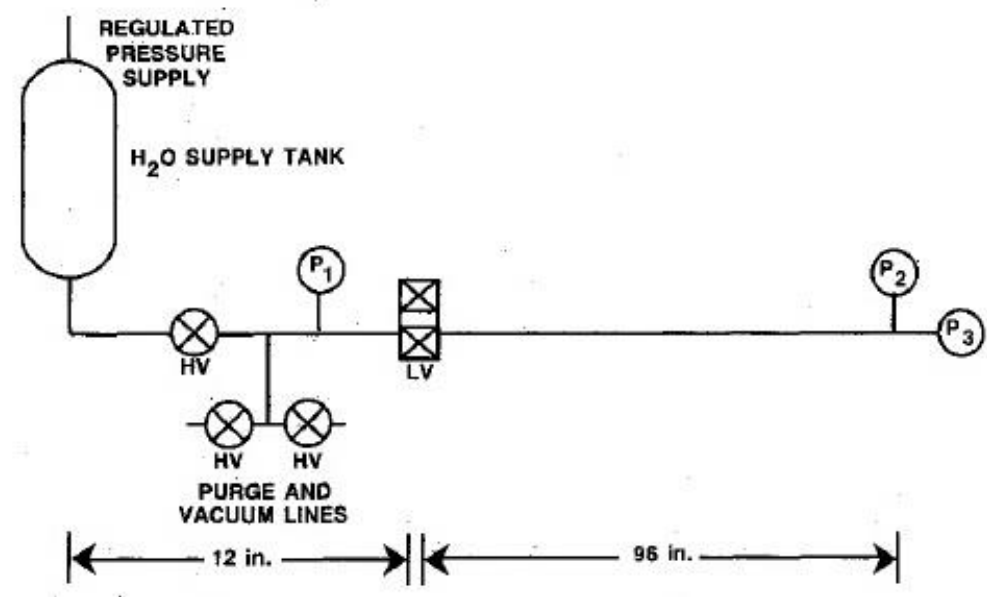

Figure 4. Schematic of Single Feed Line (courtesy: Pricket et al [7])

The physical problem is converted into the GFSSP's numerical model by dividing the entire domain into 8 pipe segments, and a restriction for the latch valve as shown in figure 4 below.

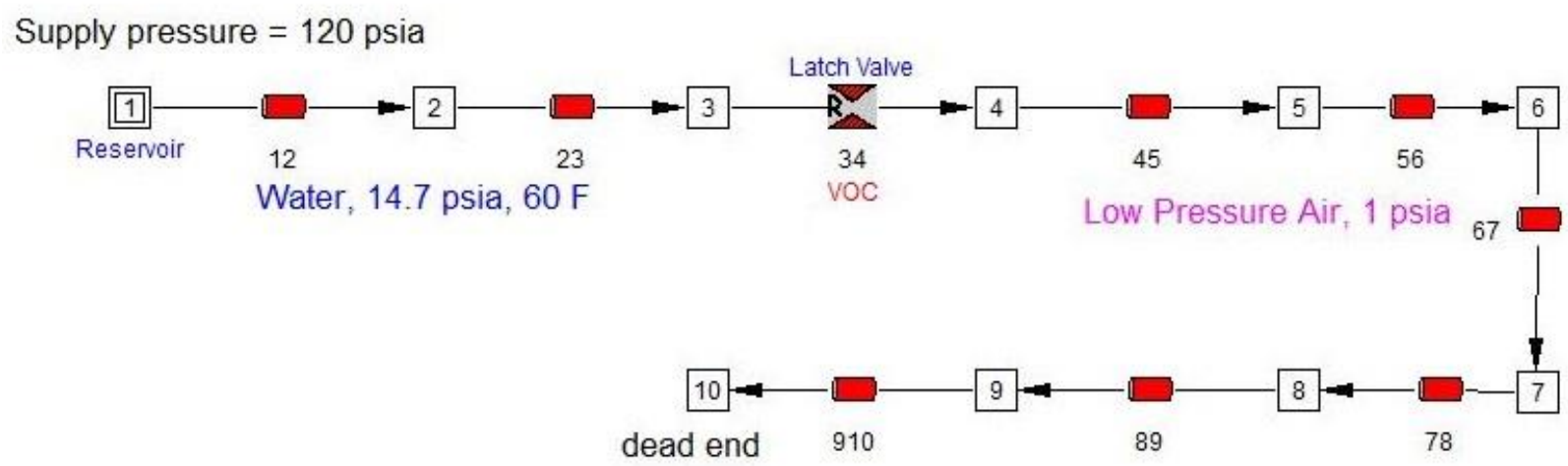

Figure 5. Computational Domain for the Single Feed Line

In order to model initially evacuated line downstream of the latch valve, air at very low pressure is assumed to be present in the pipe line, and the initial pressure of air $\left(\mathrm{p}_{\text {air }}\right)$ is a numerical adjusting parameter. In the current simulation this pressure is varied and gradually lowered to see when the numerical solution is virtually independent to this pressure. This is discussed in the results and discussion section later.

The last and the third case considered in the current work is priming in a flow network consisting several components as shown in figure 6 below. The network is quite complex and consists of several hand valves (HV), latch valve (supply valve), volume reservoirs (indicated by V1 through V4), and pipe lines. The fluid (water) flows from a reservoir through the hand valve (HV1) and controlled by the latch valve (indicated by R1) and it branches out into three directions: a) going straight to hand valve 2 (HV11), which is considered a dead end to compare with one of the test run of Pricket et al, b) branching out through hand valve HV3, and ending into a volume reservoir, and c) branching out through a filter and rest of the network. The volume of the reservoirs are given in the table 1 . The hand valves are used for control of system purging and evacuation. In the current numerical model they are assumed to be fully open. 


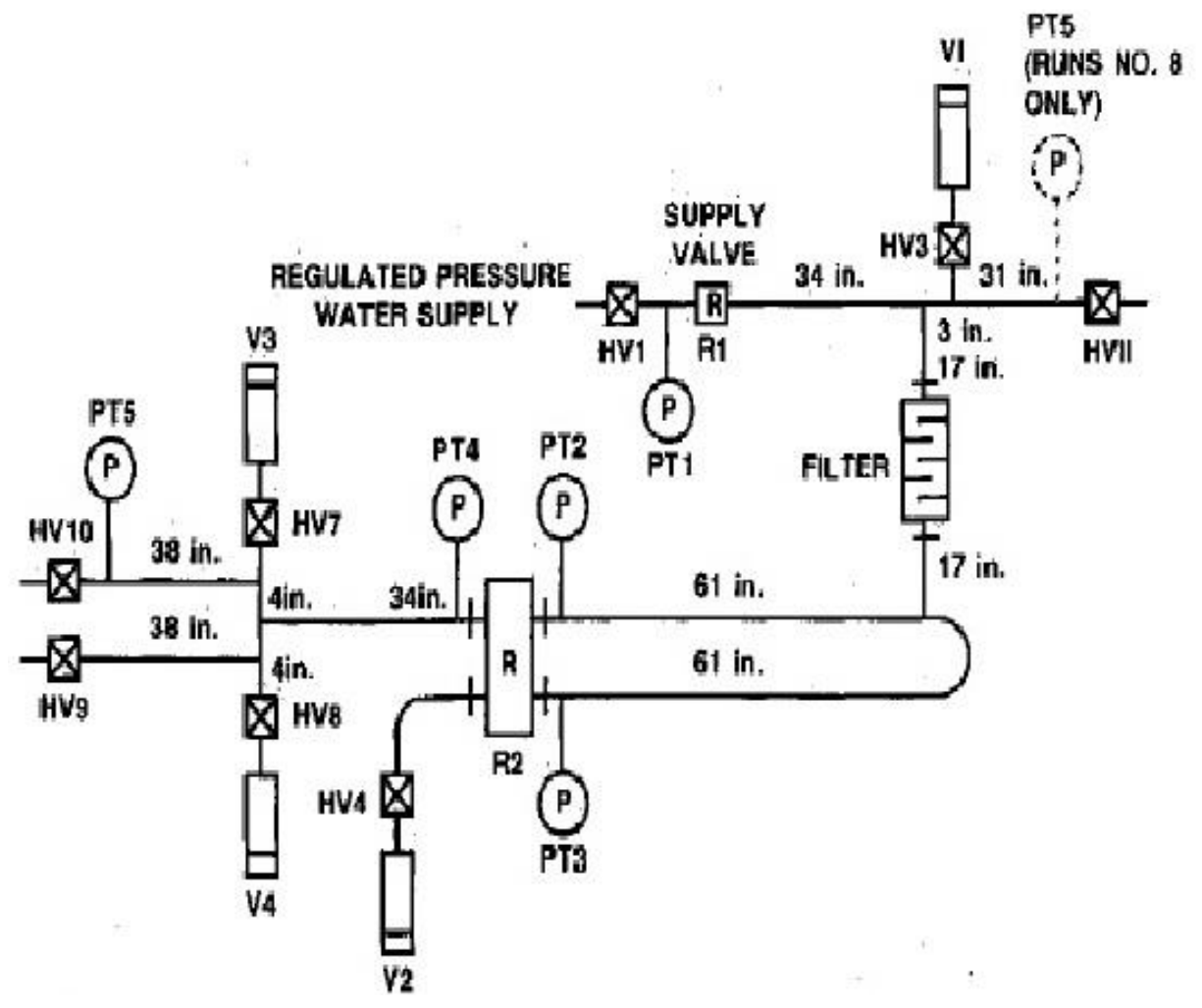

Figure 6. Schematic of a flow network (courtesy: Prickett et al)

\begin{tabular}{|c|c|}
\hline Volume Reservoir & Volume in inch $^{3}$ \\
\hline V1 & 3.55 \\
\hline V2 & 14.55 \\
\hline V3 & 5.68 \\
\hline V4 & 4.68 \\
\hline
\end{tabular}

Table 1. Volume Reservoir Information

The filter as shown in figure 6 above, is a liquid filter in which etched disk are stacked in a titanium casing, and the filter specification is given in table 2 below.

\begin{tabular}{|l|c|}
\hline Filtration Rating & $10 \mu \mathrm{m}$ \\
\hline Internal Volume & $0.915 \mathrm{in}^{3}$ \\
\hline Pressure Drop & $\Delta \mathrm{p}$, psia $=15.92(\mathrm{GPM})^{1.18}$ \\
& $\mathrm{GPM}=$ discharge rate in gallons per min \\
\hline
\end{tabular}

Table 2. Liquid Filter Specifications

In the network, the main supply valve as indicated by $\mathrm{R} 1$ in figure 6 , is a latch valve which opens instantaneously allowing the fluid to enter into the network from the main reservoir. There is another set of valves called the replacement component, indicated as R2 in the figure, is an attachment that can have different type of flow attachments (orifice, valves etc.) as used for testing by Prickett et al. For the current simulation, it is assumed that there are a pair of control valves that are initially open, but closes sharply at about 0.5 second, to see the effect of it on the water hammer pressure surges. The supply pressure varies, and for the current simulation 240 psia is 
used as supply pressure as that was one of the worst case scenario regarding system failure as reported by Prickett et al in their experimental work.

Computational Model for the Flow Network is shown below in figure 7. Node 1 is the boundary node representing supply reservoir, and the volume reservoirs are labelled V1 through V4 in the figure.

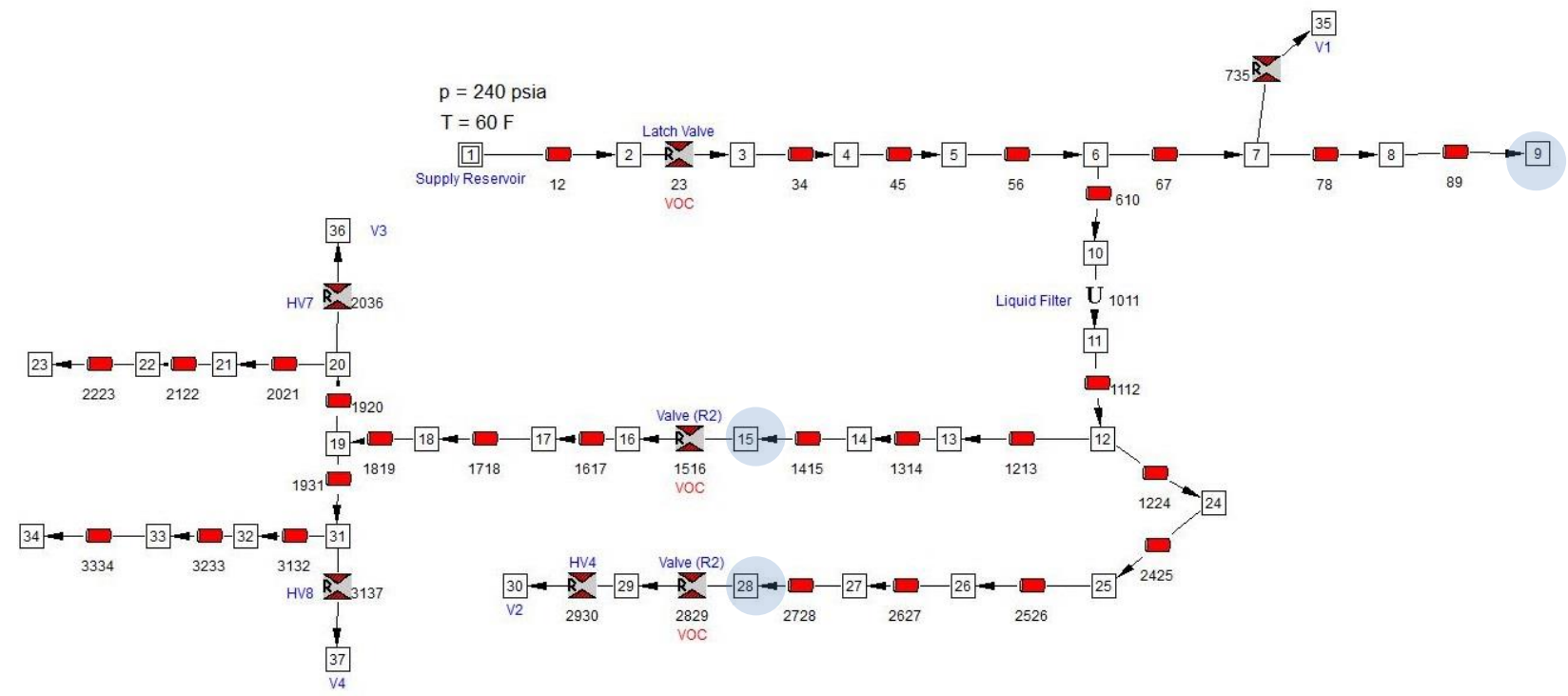

Figure 7. Computational Domain for the Flow Network

As hand valves 9, 10 and 11 were not used and the pipe line are assumed to be closed in the specific testing by Pricket el al, those are not considered in the current computational model. Nodes 9, 15 and 28 are highlighted as these are the nodes where the simulations results are monitored. The liquid filter is modeled by using the correlation for pressure drop given in table 2 , and suitably converting into the form:

$$
\Delta P=K_{f} \dot{m}^{2} \text {. }
$$

\section{Results and Discussion}

The computational results are presented separately for all the three different case studies as mentioned in the earlier section In all three cases, the primary interest is finding the pressure distribution, and the results are reported at the locations consistent with the locations where test data are available in the literature for comparison.

Case Study 1: Water hammer in straight pipe with entrapped air

The first case study is the water hammer into a pipe with entrapped air. The two most important input parameters for this study are: $\mathrm{P}_{\mathrm{R}}=\mathrm{p}_{\mathrm{R}} / \mathrm{p}_{\mathrm{atm}}$ and $\alpha=\mathrm{L}_{\text {air }} / \mathrm{L}_{\text {tot }}$. Based on the value of $\alpha$, three different geometrical configuration with initial air column length of $16.23 \mathrm{ft}(\alpha=0.448), 4.85 \mathrm{ft}(\alpha=0.195)$, and $1.23 \mathrm{ft}(\alpha=0.058)$ are considered for the study. As obtained from Lee's [9] experimental study, the experimental measurements of pressure at three different locations along the pipe are available. Two of these locations are at the ball valve and dead end. For the first geometrical case $\left(\mathrm{L}_{\mathrm{air}}=16.23 \mathrm{ft}\right)$, the additional location is at midair and for the other two geometrical case the third location is at about mid water (10.9 ft from the pipe entrance location). Figures 9, 10 and 11 show the comparison of current numerical results with the measured data for Lee [9] for the three different $\alpha$ values. Results qualitatively match quite well in all the cases, except for the peak pressure is about $20 \%$ off from in the worst case. The frequency of pressure oscillations match quite well for most of the cases- 


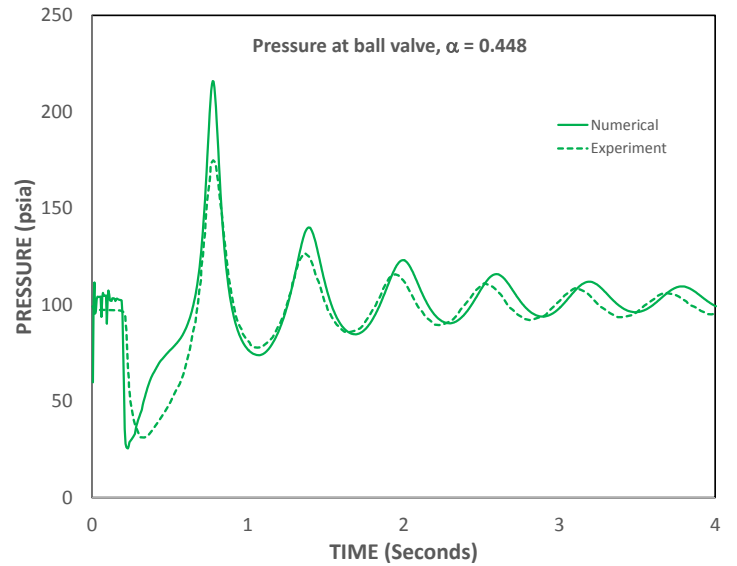

(a)

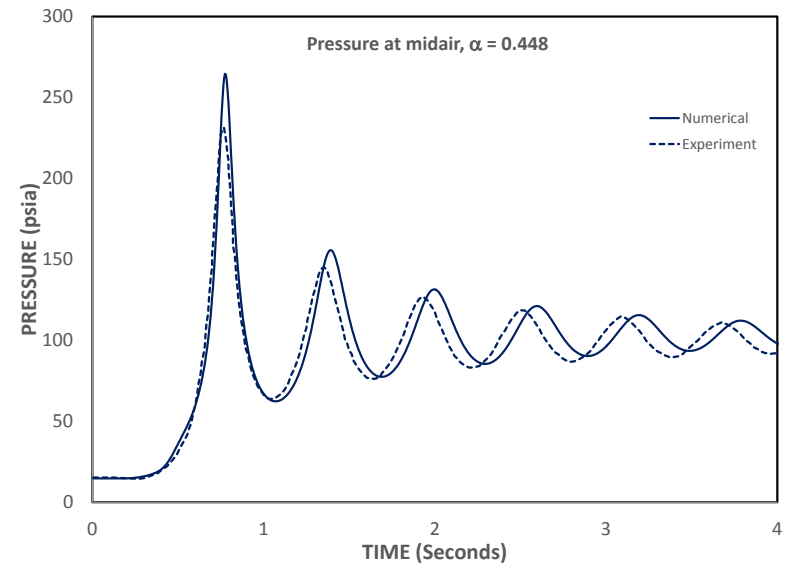

(b)

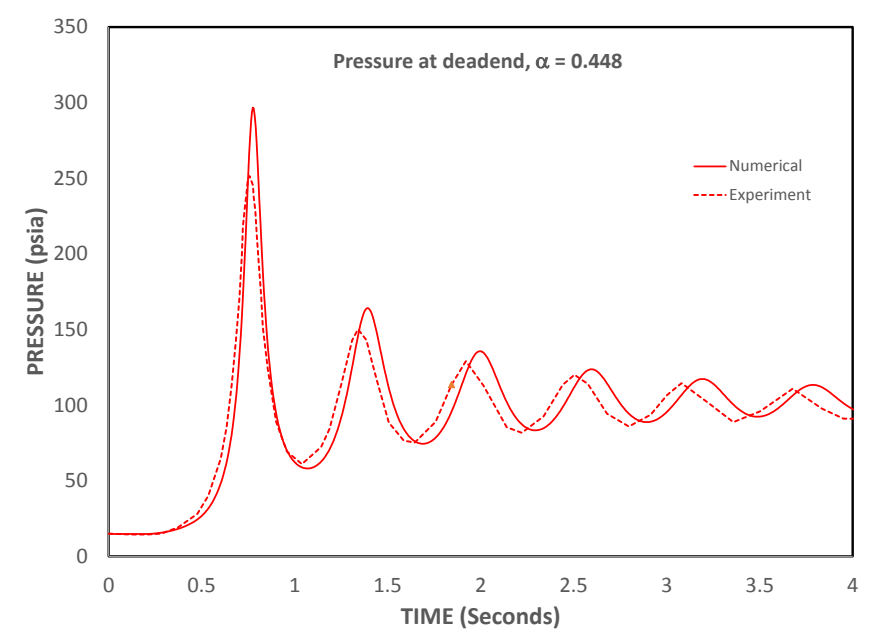

(c)

Figure 9. Pressure at (a) ball valve (b) midair and (c) dead end for $\mathrm{P}_{\mathrm{R}}=7$ and $\alpha=0.448$
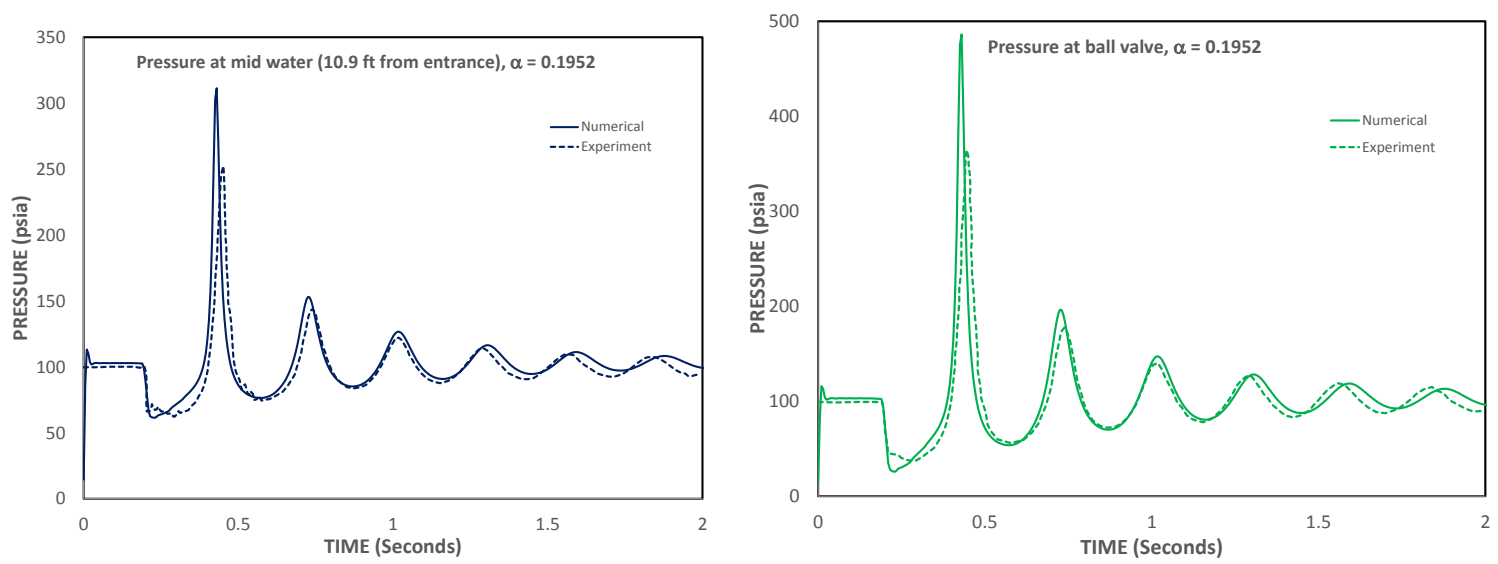


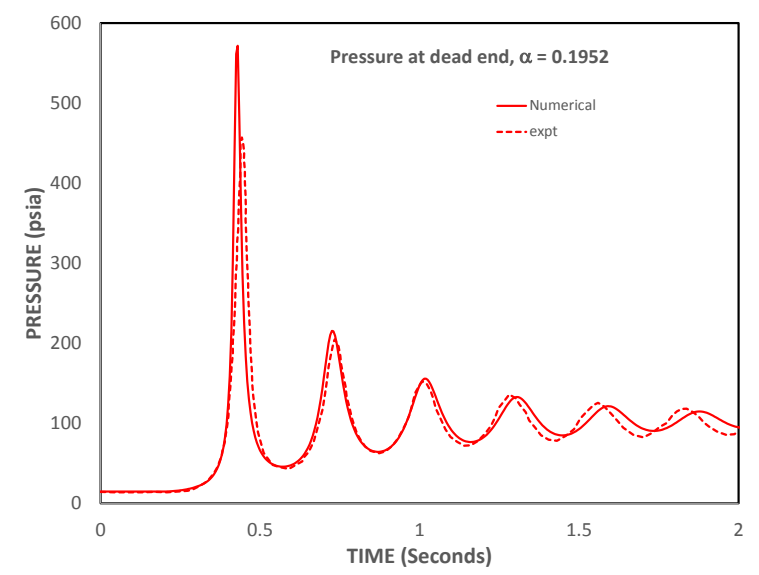

Figure 10. Pressure at (a) midwater (b) ball valve and (c) dead end for $P_{R}=7$ and $\alpha=0.1952$
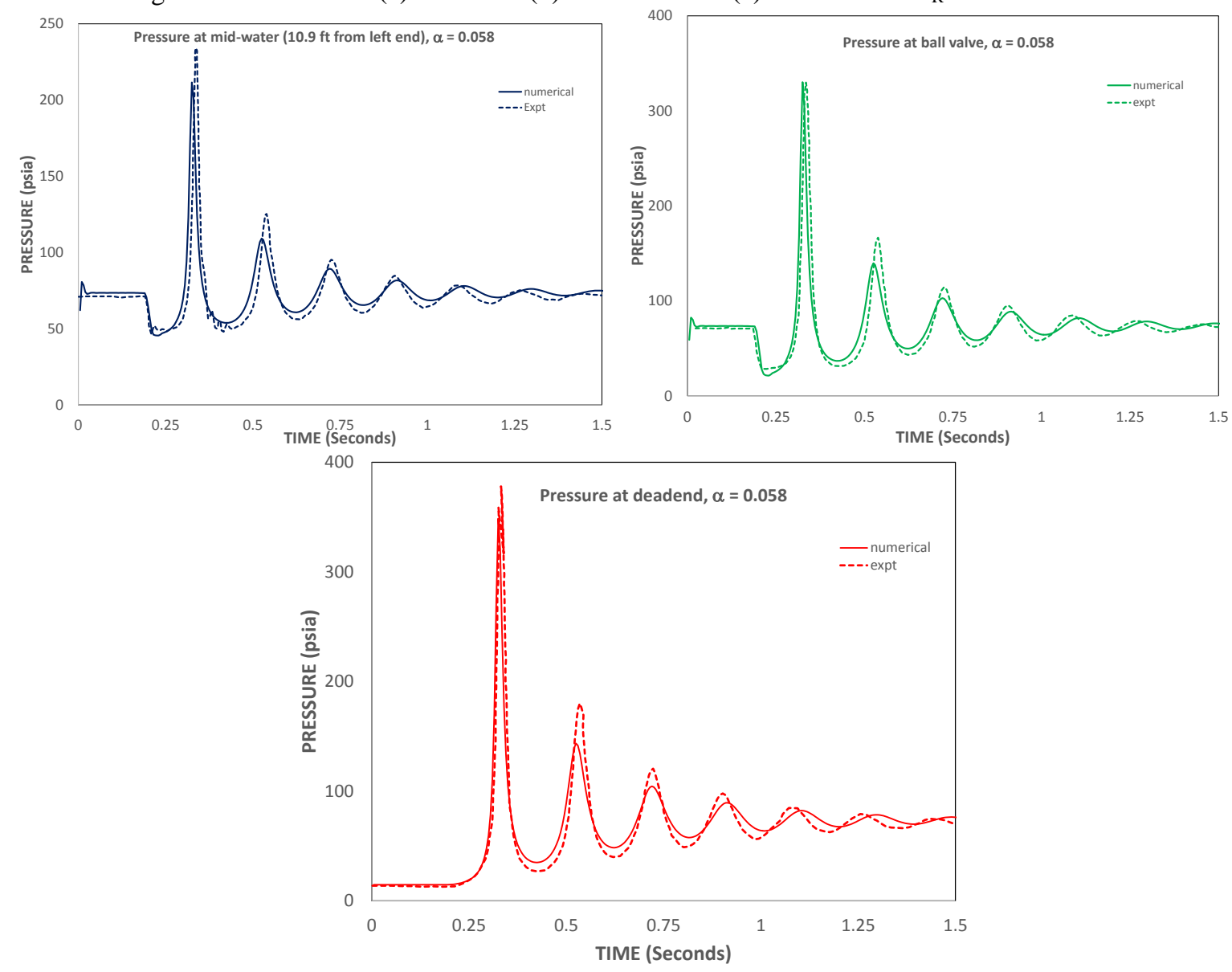

Figure 11. Pressure at (a) mid-water, (b) ball valve and (c) dead end for $P_{R}=5$ and $\alpha=0.058$

Case Study 2: Priming in evacuated straight pipeline

Two of the most important parameter in priming problem is the peak pressure and the impact time. The current numerical algorithm is validated against the test data for a supply pressure of 120 psia for which the peak pressure of 2350 psia and impact time of 0.17 seconds are measured by Prickett et al in their test facility. The current numerical model of using two fluids, the pressure in the air region is varied in order to obtain a virtually evacuated condition when the numerical value of peak pressure does not change appreciably. Another important numerical parameter in this transient study is the time step. A time step of $0.1 \mathrm{~ms}$ (milliseconds) and air pressure of 1 psia are used as optimized parameter so as to obtain a numerically time step independent result in idealized situation of evacuated 
line. Figure 12(a) and (b) show this parametric study to obtain the optimized time step and downstream air pressure respectively.
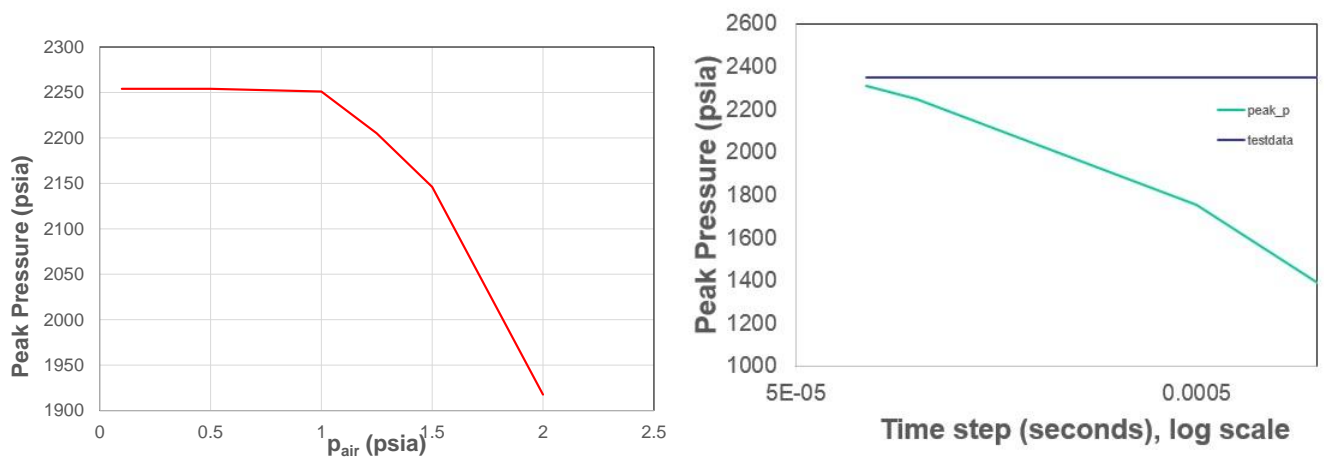

Figure 12. Optimization of the numerical parameters

For all the plots in the current simulation, time step of 0.1 millisecond and air pressure of 1 psia is being used. The maximum pressure rise occurs at the dead end and at time $=0.176$ seconds as shown in figure 13 ( $\mathrm{A}$ and $\mathrm{B}$ ) below. Both the diagram represent same plots, $\mathrm{A}$ is enlarged view of $\mathrm{B}$, in the neighborhood of peak pressure domain. The peak pressure is 2279 psia as compared to experimental data of $2350 \mathrm{psia}$. In fact the numerical results go even closer to the experimental data and is 2330 psia when the time step is reduced further to 0.075 second. However, lowering the time step causes numerical convergence issue. The impact time, the time taken to reach the maximum after the valve is opened is 0.173 second, which matches very well with the experimental result of 0.170 second.
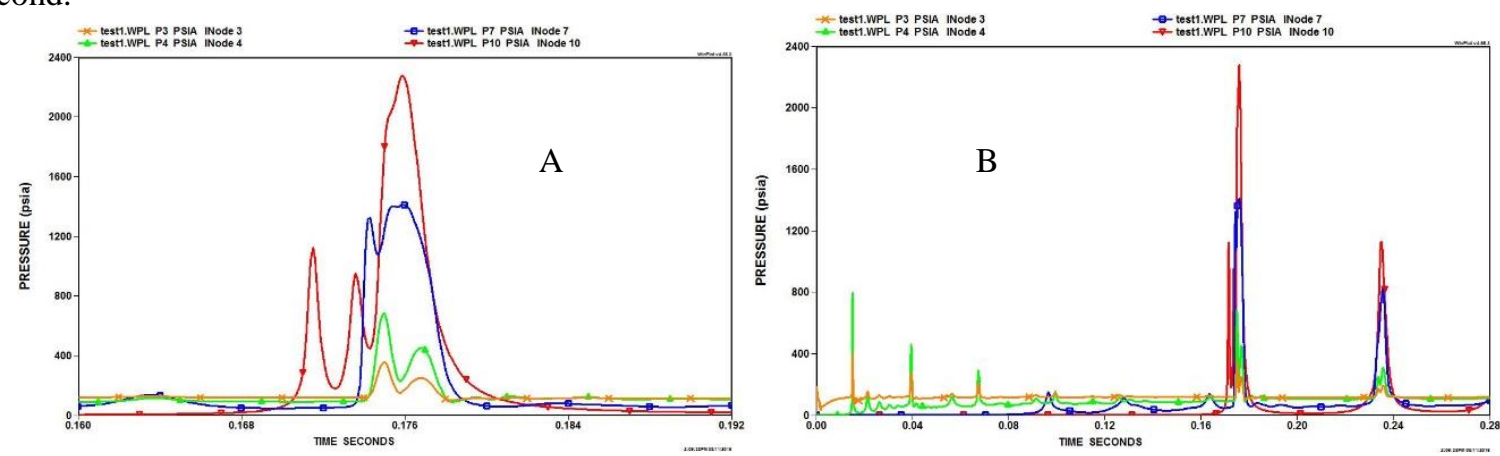

Figure 13. Pressure at various nodes

Case Study 3: Priming in a flow network

The pressure distribution in the straight region and in the branches are shown in figures 14 and 15 respectively. 


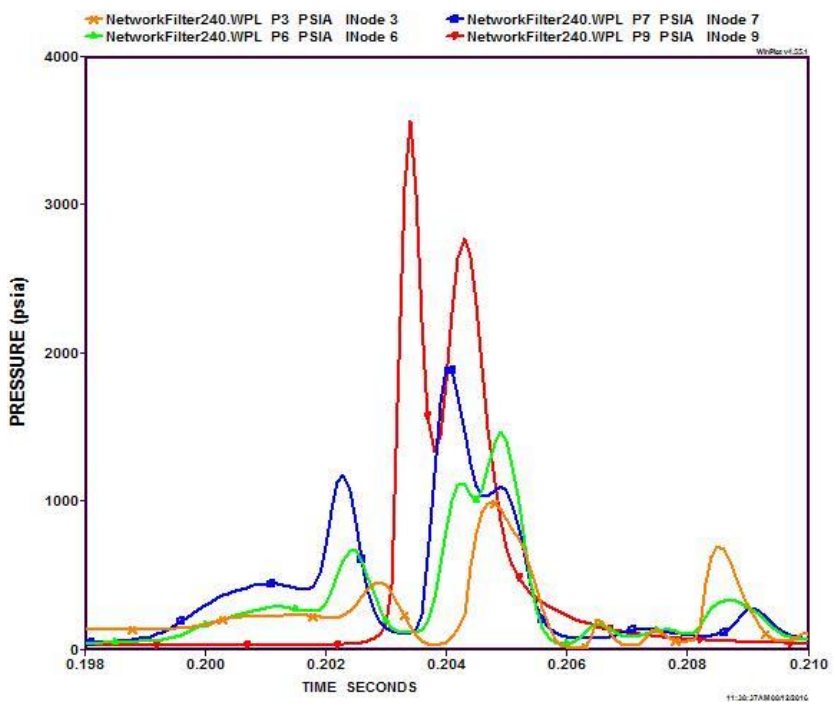

Figure 14. Pressure Distribution in Straight Branch

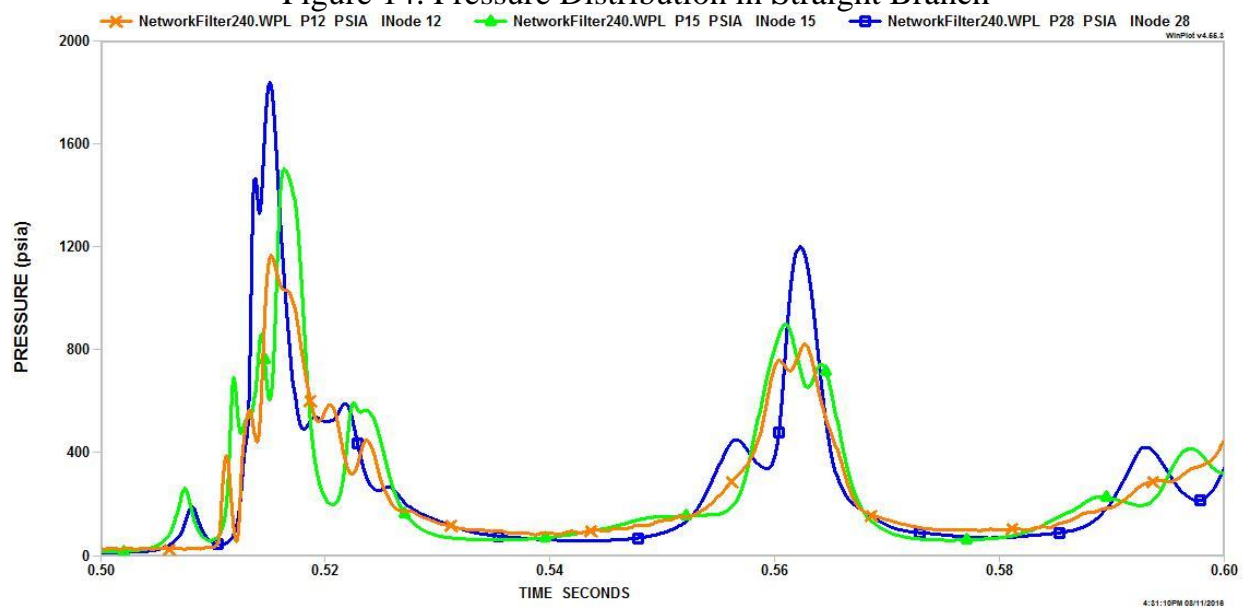

Figure 15. Pressure Distribution in Bottom Branches, near the valve closing region.

The peak pressure occurs at the dead end of the straight branch, and numerically it is found to be little above 3500 psia. The pressure on the bottom branch, the peak occurs at node 28 and is found to be 1837 psia as compared to test data as reported by Prickett et al as 1800 psia. The peak pressure at dead end (node 9) can further be reduced using uinsteady friction factor model $[11,12]$ as shown in figure 16 below. Overall, the numerical prediction matches well with experimental data. However, due to lack of information from the literature the peak pressure at node 9 could not be compared. The pressure distribution in the frequency domain is obtained using a fast Fourier transformation and is shown in figure 17 below.

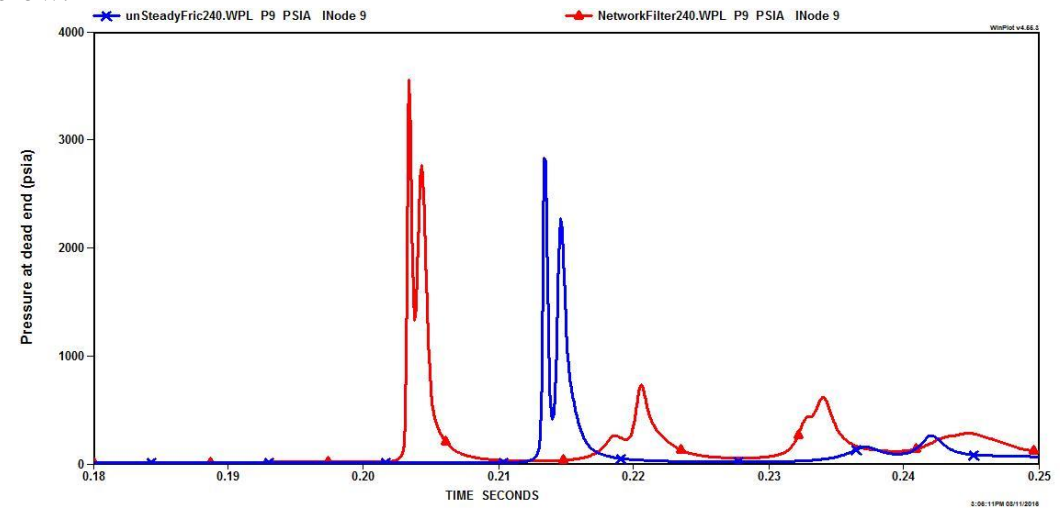

Figure 16. Comparison between two different friction factor model 


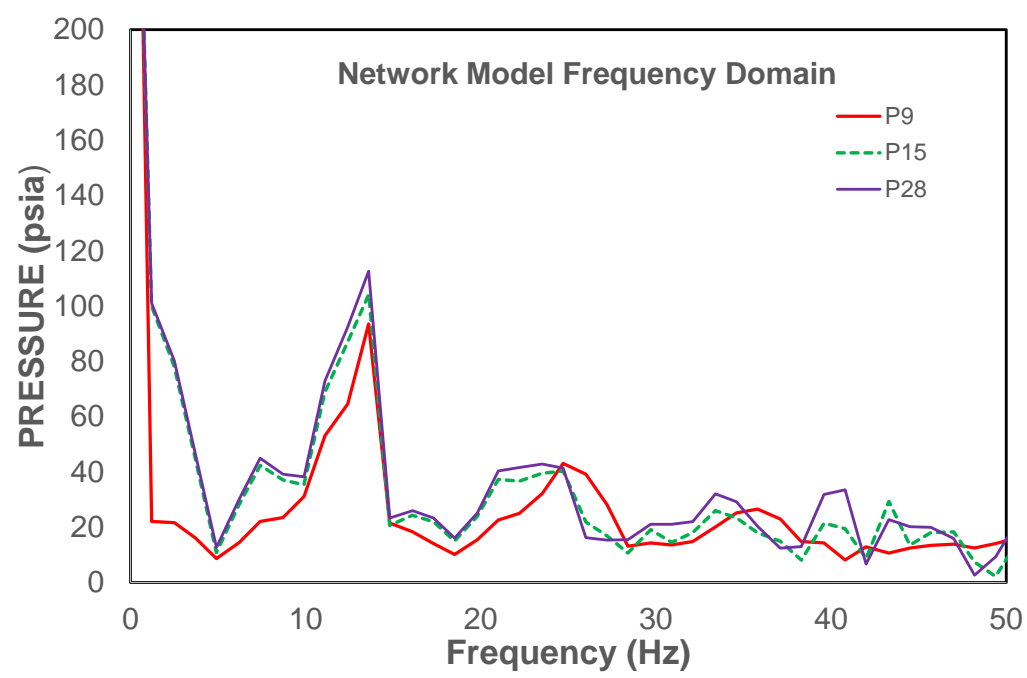

Figure 17. Pressure in frequency domain

\section{IV.Conclusions}

The two-fluid model produced very good agreement in all three case studies. The pressure at various locations, both upstream and downstream of the valve are computed and compared with measured data of Lee [9] for the entrapped air problem. The frequencies match very well except the peak pressure are slightly over predicted, a maximum of $18 \%$ error is found. The priming in straight pipe, the numerical prediction match very well with less than $1 \%$ error. The unsteady friction factor helped reducing the peak pressure in the network model. There needs to be more testing done in this regard using the unsteady friction model. The work can be extended for water hammer analysis with real propellants which can be of more practical and real space craft use.

\section{Acknowledgments}

This work was supported by a fellowship awarded to Dr. Alak Bandyopadhyay under the NASA Summer Faculty program. The work was conducted at MSFC, Huntsville, Alabama, in the ER43/Thermal Analysis Branch.

\section{References}

${ }^{1}$ Ghidaoui M.S., Zhao M., Mclnnis D.A., and Axworthy D.H, "A review of water hammer theory and practice”, Trans. ASME, Jan. 2005, vol. 58, pp 49-76.

${ }^{2}$ Lin, T.Y., Baker, D., “Analysis and Testing of Propellant Feed System Priming Process,” J. Propulsion Power, Vol. 11, No. 3, pp. 505-512, May-June 1995.

${ }^{3}$ Hearn, H.C., Development and application of a priming surge analysis methodology, Proc. 41st AIAA/ASME/SAE/ASEE Joint Propulsion Conf. \& Exhibit, Tucson, AZ, pp. 1-10, July 10-13, 2005.

${ }^{4}$ Majumdar, A.K., Flachbart, R.H., "Numerical modeling of fluid transients by a finite volume procedure for rocket propulsion systems," Proc. ASME FEDSM'03, 4th ASME/JSME Joint Fluids Eng. Conf., Honolulu, HI, pp. 1-8, July 6-10, 2003.

${ }^{5}$ Pinho J., Lema M., Rambaud P., and Steelant J., "Multiphase Investigation of Water Hammer Phenomenon Using the Full Cavitation Model", Journal of Propulsion and Power, Vol. 30, No. 1 (2014), pp. 105-113.

${ }^{6}$ Prickett, R.P., Mayer, E., and Hermel, J., "Water Hammer in Spacecraft Propellant Feed Systems", AIAA-88-2920, Journal of Propulsion and Power, vol. 8, no. 3, May-June 1992, pp.592-597.

${ }^{7}$ Lecourt R., and Steelant J. "Experimental Investigation of Water hammer in Simplified Feed Lines of Satellite Propulsion Systems", Journal of Propulsion and Power, Vol. 23, No. 6 (2007), pp. 1214-1224.

${ }^{8}$ Alak Bandyopadhyay and Alok Majumdar. "Network Flow Simulation of Fluid Transients in Rocket Propulsion Systems", Journal of Propulsion and Power, Vol. 30, No. 6 (2014), pp. 1646-1653 
${ }^{9}$ Lee, N.H., "Effect of Pressurization and Expulsion of Entrapped Air in Pipelines", Ph.D. thesis, Georgia Tech., August 2005.

${ }^{10}$ Lee, N. H., and Martin, C. S. (1999). "Experimental and analytical investigation of entrapped air in a horizontal pipe." Proc., 3rd ASME/JSME Joint Fluids Engineering Conf., ASME, New York, 1-8.

${ }^{11}$ Brunone, B., Kearney, W., Mecarelli, M., Ferrante, M., "Velocity Profiles and Unsteady Pipe Friction in Transient Flow," J. Water Resource Planning and Management, Vol. 126, No. 4, pp. 236-244, 2000.

${ }^{12}$ Dehkordi, M.M., Firoozabadi, B.D., "Effects of Unsteady Friction Factor on Column Separation,” Proc. IMECE 2007, ASME International-Mechanical Engineering Congress and Exposition, Seattle, WA, pp. 1-7, Nov. 2007 